\title{
Speciation of heavy metals during co-composting of livestock manure
}

\author{
Shazia Gul ${ }^{\text {** }}$, Alia Naz ${ }^{1}$, Iftikhar Fareed ${ }^{2}$, Abdullah Khan ${ }^{1}$, Muhammad Irshad ${ }^{3 *}$ \\ ${ }^{1}$ University of Haripur, Department of Environmental Sciences, Hattar Road Haripur, Pakistan \\ ${ }^{2}$ University of Kurdistan, Department of Natural Resources Engineering and Management, Hewler, Iraq \\ ${ }^{3}$ COMSATS Institute of Information Technology, Department of Environmental Sciences, Abbottabad, Pakistan \\ "Corresponding authors: e-mail: mirshad@ciit.net.pk,786shaziagul@gmail.com
}

\begin{abstract}
Heavy metals determination in manures provides beneficial information to predict the availability and the potential contamination of environment. Therefore, a study was carried out to investigate heavy metals changes in livestock manure during a co-composting process. The metals were stepwise fractionated into exchangeable, adsorbed, organically bound, carbonate precipitated and residual forms by extracting with $0.5 \mathrm{M} \mathrm{KNO} \mathrm{KN}_{3}$, de-ionized water, $0.5 \mathrm{M} \mathrm{NaOH}, 0.05 \mathrm{M} \mathrm{Na}_{2}$ EDTA and $4 \mathrm{M} \mathrm{HNO}_{3}$, respectively. During the extraction process, the amount of metals remained highly dependent on an extraction method and stage of manure composting. Extractions released heavy metals contents in the final composted manure as $\mathrm{Zn}>\mathrm{Cu}>\mathrm{Pb}>\mathrm{Cr}>\mathrm{Ni}>\mathrm{Cd}$. Irrespective of the days of composting, extracting agents differed in the order $\mathrm{HNO}_{3}>\mathrm{Na}_{2} \mathrm{EDTA}>\mathrm{NaOH}>\mathrm{KNO}_{3}>\mathrm{H}_{2} \mathrm{O}$ for all heavy metals. Higher concentrations of heavy metals were observed during the early stages of composting. Conversely, there was a progressive increase in the concentrations of $\mathrm{K}, \mathrm{Ca}$ and $\mathrm{Mg}$ during composting of manure. Total $\mathrm{C}$ in the manure reduced with composting days.
\end{abstract}

Keywords: heavy metals, fractionation, composting, manure, temporal changes.

\section{INTRODUCTION}

The utilization of manure is an integral part of sustainable agriculture. Animal manures have been used as fertilizers for centuries ${ }^{1}$. Sewage sludge and manure are the most common organic wastes applied either raw or composted. The application of organic wastes to the soil provides nutrients, increases organic matter, improves soil structure, and increases nutrient absorption by plants effectively ${ }^{2,3}$. The composting of organic waste is a system for the frequent biological decomposition of organic materials, with a resulting total loss of total organic matter and concentration of the inorganic constituents. Composting reduces the volume and weight of the raw material, with a resulting stable product, which can be widely used in agriculture. This can also minimize the impact of several environmental problems. However, the quality of the compost depends on the presence or absence of inorganic and organic pollutants, which could enter the food-chain by the plant uptake ${ }^{4}$.

Compost is applied as a measure for improving soil quality and fertility; although the presence of heavy metals can restrict its uses due to health or environmental concerns. Heavy metals in soil can be divided into two fractions (i) inert fraction, assumed as the nontoxic fraction, and (ii) the labile fraction, assumed to be relatively toxic. To assess the availability of heavy metals, only the soil labile fraction is considered into account because this fraction is usually called the bioavailable fraction ${ }^{5}$. The determination of total heavy metals concentration does not give useful information about problems of bioavailability, toxicity, capacity for remobilization of heavy metals in the environment and chemical forms of a metal in which they are present in the composting process ${ }^{6}$.

The determination of the chemical species is a major problem and sometimes become impossible. Therefore, the use of sequential extraction procedures for the determination of the different chemical forms or ways of binding between trace metals and soil components gives an effective implement during environmental studies ${ }^{7}$. Sequential chemical fractionation techniques distinguish trace elements into different fractions through a series of chemical reagents ${ }^{\mathbf{8}, 9}$. There have been very little data published on the fractionation of heavy metals during co-composting process, either during the thermophilic phase or the maturation phase or both ${ }^{\mathbf{1 0}}$. Therefore, the present study was initiated to investigate the speciation of heavy metals in livestock manure during a co-composting process.

\section{EXPERIMENTAL}

Manure samples after composting process of $0 \mathrm{~d}$, $40 \mathrm{~d}, 80 \mathrm{~d}$ and $120 \mathrm{~d}$ were collected from Higo Organic Factory located near Haripur, Pakistan. In composting plant, livestock manure was co-composted with plants residues (3: 1). The moisture contents of the compost were controlled to an approximate level of $20 \%$ at room temperature under aerobic conditions. Occasionally the manure was pulverized mechanically. The manure samples were brought to the laboratory, air-dried and sieved through a $2 \mathrm{~mm}$ sieve and stored in a polythene bags. Carbon contents in the samples were measured by combustion method at $550^{\circ} \mathrm{C}$ for $2 \mathrm{~h}$. The $\mathrm{pH}$ and electrical conductivity (EC) were measured in 1: 5 sample- $\mathrm{H}_{2} \mathrm{O}$ suspensions by $\mathrm{EC}$ meter and $\mathrm{pH}$ meter, respectively. Macro- and micro-elements [calcium $(\mathrm{Ca})$, magnesium $(\mathrm{Mg})$, potassium $(\mathrm{K})$, zinc $(\mathrm{Zn})$, copper $(\mathrm{Cu})$, chromium $(\mathrm{Cr})$, nickel $(\mathrm{Ni})$, lead $(\mathrm{Pb})$, cadmium $(\mathrm{Cd})]$ were determined using an atomic absorption spectrophotometer (AAS).

\section{Sequential extraction of heavy metals}

The sequential extraction of heavy metals from the composted manure was carried out in triplicate using $0.5 \mathrm{~g}$ of each manure samples in $50 \mathrm{~mL}$ centrifuge tubes. Modified version of sequential extraction procedure was used to fractionate heavy metals ${ }^{11}$. The heavy metals were fractionated into exchangeable, adsorbed, 
organically bound, carbonate precipitated and residual forms by using five different extraction buffers: i) 0.5 $\mathrm{M} \mathrm{KNO}_{3}, 16$ hours, ii) de-ionized water shaking for 2 hours (extracted three times and combined), iii) $0.5 \mathrm{M}$ $\mathrm{NaOH}$ for $16 \mathrm{~h}$, iv) $0.05 M \mathrm{Na}_{2}$ EDTA for $6 \mathrm{~h}$, and $\mathrm{v}$ ) $4 \mathrm{M} \mathrm{HNO}_{3}$ for 16 hours at $80^{\circ} \mathrm{C}$, respectively. During each extraction the sample suspension was centrifuged at $5000 \mathrm{rpm}$ for $15 \mathrm{~min}$ and the resulting supernatant solution was decanted and filtered by a $0.22 \mu \mathrm{m}$ filter. The extracts were subjected to determine the above elements using AAS. Total heavy metals in manure samples were also determined in triple acids mixture of $\mathrm{HNO}_{3}-\mathrm{HClO}_{4}-\mathrm{H}_{2} \mathrm{SO}_{4}(4: 1: 1)$. The mixture was filtered through a filter paper. The heavy metals contents in the filtrate were determined by AAS. Data were statistically analyzed using Stat-view software ${ }^{\mathbf{1 2}}$ and results were expressed on oven-dry basis. A probability level of $<0.05$ was considered significant and means were compared by least significant difference (LSD-test).

\section{RESULTS AND DISCUSSION}

A marked decrease in the total $\mathrm{C}$ was observed during composting. Fresh manure exhibited $430 \mathrm{~g} \mathrm{~kg}^{-1}$ of total $\mathrm{C}$ concentration whereas after 120 days of composting, the concentration of $\mathrm{C}$ was observed to a level of $321 \mathrm{~g}$ $\mathrm{kg}^{-1}$ (Table 1). The amount of $\mathrm{C}$ in the manure samples was oppositely related to the days of composting. Composting is a biochemical process in which $\mathrm{C}$ and $\mathrm{N}$ are lost resulting from the oxidation of organic $\mathrm{C}$ to $\mathrm{CO}_{2}$ and loss of water. The declining trend of the $\mathrm{C}$ was similar to those reported previously ${ }^{\mathbf{1 3}, 14}$ where a decrease in the total $\mathrm{C}$ was noted after a composting process.

The major nutrients varied in the order $\mathrm{K}>\mathrm{Mg}>$ $\mathrm{Ca}$ (Table 1). There was a progressive increase in the concentrations of $\mathrm{K}, \mathrm{Ca}$ and $\mathrm{Mg}$ during composting. These increases were possibly due to the concentration effect as compost volume decreased with days accompanied by the losses of the more volatile elements such as carbon and nitrogen under aerobic conditions. The fluctuation observed in the release of these soluble nutrients could be attributed to the variations in the microbial activity and $\mathrm{C} / \mathrm{N}$ ratios of the manure samples. Eneji et al. ${ }^{14}$ also reported increased total plant nutrients with time of composting under both aerobic and anaerobic conditions.

A marked increase in the EC value was observed during composting. Manure showed a slight increase in the $\mathrm{pH}$ values under composting process (Table 1). The $\mathrm{pH}$ of the fresh sample was 7.7 whereas the $\mathrm{pH}$ after 120 days slightly enhanced to 8.8. This increase in the $\mathrm{pH}$ values over time could be attributed to the modified chemical composition of the manure through a microbial action. Petruzzelli ${ }^{\mathbf{1 5}}$ and Caviatti et al. ${ }^{\mathbf{1 6}}$ reported that increasing the $\mathrm{pH}$ of compost lowered the availability of heavy metals. Wong and Fong ${ }^{17}$ reported the bioavailability of heavy metals by increasing the $\mathrm{pH}$ of the compost mass and found that $\mathrm{Fe}-\mathrm{Mn}$ oxide bound $\mathrm{Pb}$ increased during composting.

Concentrations of heavy metals were varied according to the days of composting. Irrespective of the stage of composting total heavy metals contents in the final

Table 1. Changes in chemical composition of manure during composting

\begin{tabular}{|c|c|c|c|c|c|}
\hline Parameters & Fresh & $40 \mathrm{~d}$ & $80 \mathrm{~d}$ & $120 \mathrm{~d}$ & LSD (0.05) \\
\hline Total C $\left[\mathrm{g} \mathrm{kg}^{-1}\right]$ & 430.7 & 383.8 & 357.5 & 321.4 & 4.3 \\
\hline Total Ca $\left[\mathrm{mg} \mathrm{kg}^{-1}\right]$ & 157.4 & 165.9 & 236.7 & 210.0 & 16.8 \\
\hline Total $\mathrm{Mg}\left[\mathrm{mg} \mathrm{kg}^{-1}\right]$ & 176.2 & 269.5 & 317.2 & 365.7 & 12.7 \\
\hline Total $\mathrm{K}\left[\mathrm{mg} \mathrm{kg}^{-1}\right]$ & 725.5 & 865.7 & 890.8 & 956.6 & 14.8 \\
\hline $\mathrm{EC}\left[\mathrm{dS} \mathrm{m^{-1 } ]}\right.$ & 3.4 & 3.6 & 3.9 & 4.0 & 0.3 \\
\hline $\mathrm{pH}[1: 5]$ & 7.7 & 7.6 & 8.2 & 8.8 & 0.7 \\
\hline
\end{tabular}

Table 2. Changes in $\mathrm{Zn}$ and $\mathrm{Cu}$ fractions of manure during composting

\begin{tabular}{|c|c|c|c|c|c|c|c|}
\hline \multirow{6}{*}{ Heavy metal } & \multirow{2}{*}{ Composting days } & $\mathrm{KNO}_{3}$ & $\mathrm{H}_{2} \mathrm{O}$ & $\mathrm{NaOH}$ & EDTA & $\mathrm{HNO}_{3}$ & $\mathrm{HNO}_{3}-\mathrm{HClO}_{4}-\mathrm{H}_{2} \mathrm{SO}_{4}$ \\
\hline & & \multicolumn{6}{|c|}{$\mathrm{mg} \mathrm{kg}^{-1}$} \\
\hline & 0 & 2.43 & 1.63 & 7.56 & 5.58 & 13.26 & 67.61 \\
\hline & 40 & 2.23 & 1.53 & 6.32 & 5.67 & 11.02 & 62.63 \\
\hline & 80 & 2.14 & 1.34 & 6.67 & 4.50 & 11.06 & 60.04 \\
\hline & 120 & 2.30 & 1.35 & 5.60 & 4.10 & 9.41 & 54.43 \\
\hline \multirow{6}{*}{$\mathrm{Cu}$} & LSD (0.05) & 0.03 & 0.28 & 0.15 & 0.06 & 1.00 & 1.61 \\
\hline & 0 & 2.33 & 1.82 & 8.36 & 3.47 & 7.89 & 25.43 \\
\hline & 200 & 1.83 & 1.80 & 5.46 & 3.46 & 7.43 & 18.91 \\
\hline & 400 & 1.79 & 1.76 & 3.75 & 2.38 & 6.78 & 16.82 \\
\hline & 600 & 1.75 & 1.70 & 2.26 & 2.89 & 7.10 & 19.17 \\
\hline & LSD (0.05) & 0.12 & 0.11 & 0.10 & 0.09 & 0.67 & 0.92 \\
\hline
\end{tabular}

Table 3. Changes in $\mathrm{Ni}$ and $\mathrm{Cr}$ fractions of manure during composting

\begin{tabular}{|c|c|c|c|c|c|c|c|}
\hline \multirow{6}{*}{ Metal } & \multirow{3}{*}{$\begin{array}{l}\text { Composting days } \\
0\end{array}$} & $\mathrm{KNO}_{3}$ & $\mathrm{H}_{2} \mathrm{O}$ & $\mathrm{NaOH}$ & EDTA & $\mathrm{HNO}_{3}$ & $\mathrm{HNO}_{3}-\mathrm{HClO}_{4}-\mathrm{H}_{2} \mathrm{SO}_{4}$ \\
\hline & & \multicolumn{6}{|c|}{$\mathrm{mg} \mathrm{kg}^{-1}$} \\
\hline & & 0.53 & 0.43 & 2.51 & 2.96 & 5.60 & 12.41 \\
\hline & 40 & 0.23 & 0.56 & 2.90 & 2.87 & 7.67 & 9.45 \\
\hline & 80 & 0.24 & 0.44 & 2.42 & 2.67 & 6.78 & 7.34 \\
\hline & 120 & 0.21 & 0.40 & 2.13 & 2.30 & 6.21 & 7.04 \\
\hline \multirow{6}{*}{$\mathrm{Cr}$} & LSD (0.05) & 0.02 & 0.02 & 0.10 & 0.07 & 0.45 & 0.33 \\
\hline & 0 & 1.62 & 0.78 & 2.01 & 4.97 & 7.89 & 20.87 \\
\hline & 200 & 1.64 & 0.74 & 1.69 & 4.17 & 7.78 & 19.71 \\
\hline & 400 & 1.84 & 0.67 & 1.75 & 2.40 & 7.80 & 15.91 \\
\hline & 600 & 1.48 & 0.70 & 1.80 & 2.56 & 6.56 & 12.42 \\
\hline & LSD (0.05) & 0.10 & 0.08 & 0.07 & 0.03 & 0.08 & 1.02 \\
\hline
\end{tabular}


Table 4. Changes in $\mathrm{Pb}$ and $\mathrm{Cd}$ fractions of manure during composting

\begin{tabular}{|c|c|c|c|c|c|c|c|}
\hline \multirow{6}{*}{ Metal } & \multirow{2}{*}{ Composting days } & $\mathrm{KNO}_{3}$ & $\mathrm{H}_{2} \mathrm{O}$ & $\mathrm{NaOH}$ & EDTA & $\mathrm{HNO}_{3}$ & $\mathrm{HNO}_{3}-\mathrm{HClO}_{4}-\mathrm{H}_{2} \mathrm{SO}_{4}$ \\
\hline & & \multicolumn{6}{|c|}{$\mathrm{mg} \mathrm{kg}^{-1}$} \\
\hline & 0 & 5.75 & 1.55 & 3.94 & 5.11 & 5.36 & 23.45 \\
\hline & 40 & 5.03 & 2.24 & 3.67 & 5.38 & 5.51 & 24.58 \\
\hline & 80 & 4.32 & 1.76 & 3.65 & 4.45 & 4.92 & 22.56 \\
\hline & 120 & 5.43 & 1.91 & 4.03 & 4.44 & 4.94 & 21.67 \\
\hline \multirow{6}{*}{$\mathrm{Cd}$} & LSD (0.05) & 0.02 & 0.23 & 0.15 & 0.07 & 0.56 & 0.63 \\
\hline & 0 & 0.35 & 0.35 & 0.33 & 1.69 & 1.89 & 8.93 \\
\hline & 40 & 0.28 & 0.32 & 0.29 & 1.20 & 1.78 & 9.83 \\
\hline & 80 & 0.20 & 0.18 & 0.45 & 0.85 & 1.83 & 8.45 \\
\hline & 120 & 0.23 & 0.17 & 0.14 & 0.84 & 1.78 & 8.11 \\
\hline & LSD (0.05) & 0.10 & 0.03 & 0.04 & 0.04 & 0.32 & 0.45 \\
\hline
\end{tabular}

0.5 -g manure samples in $50 \mathrm{~mL}$ centrifuge tube

$25 \mathrm{~mL}$ of $0.5 \mathrm{M} \mathrm{KNO}_{3}$, shaken for $16 \mathrm{~h}$, centrifuged and filtered
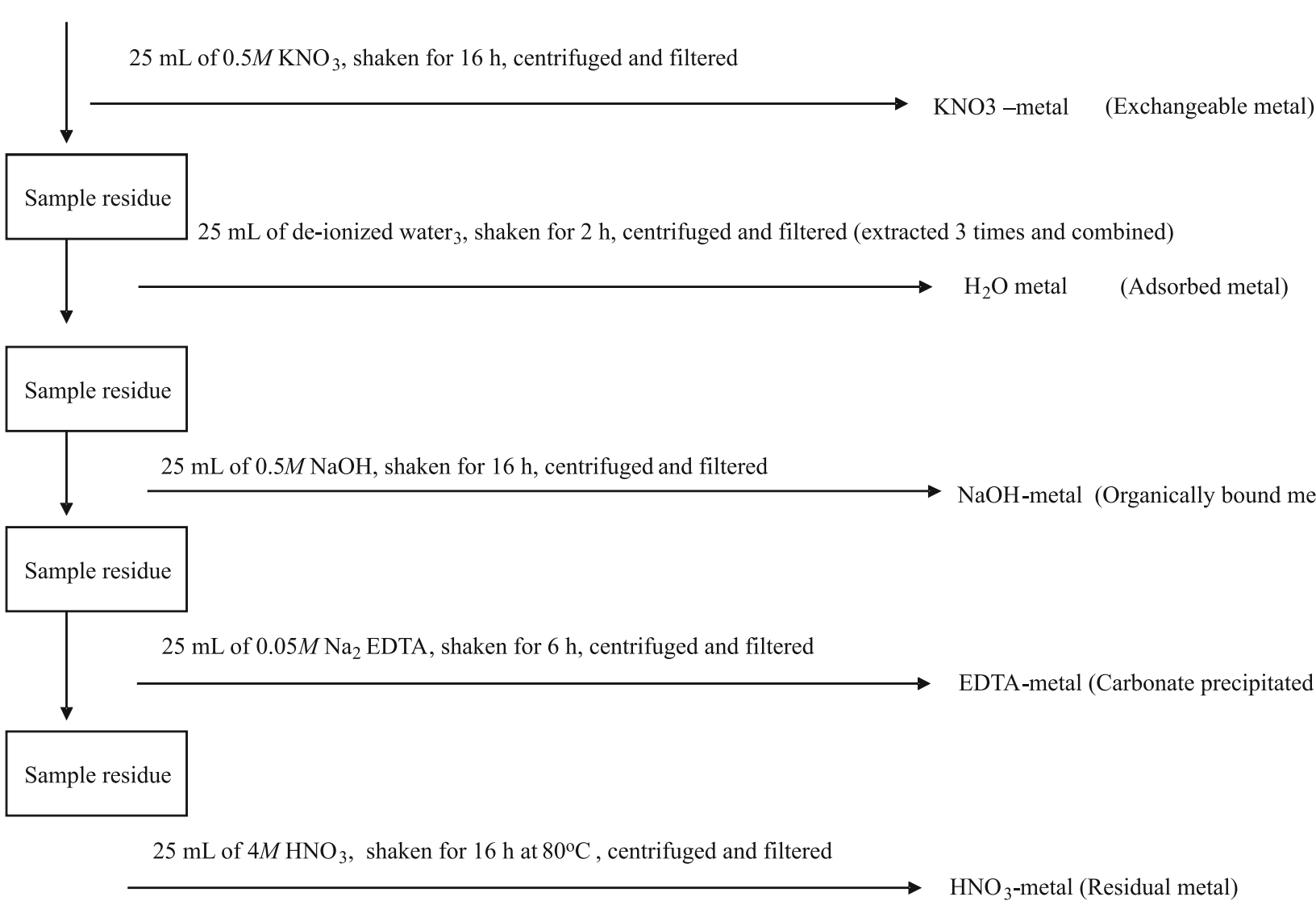

Figure 1. Schematic diagram for sequential fractionation process of metals $(\mathrm{Zn}, \mathrm{Cu}, \mathrm{Ni}, \mathrm{Pb}$ and $\mathrm{Cd})$

composted manure were varied: $\mathrm{Zn}>\mathrm{Cu}>\mathrm{Pb}>\mathrm{Cr}$ $>\mathrm{Ni}>\mathrm{Cd}$ (Table 2-4). During composting process, total heavy metals fractions decreased. This could be explained by the heavy metal losses through leaching in the course of a composting. The role of composting as important environmental sink to eliminate the most labile fraction of heavy metal is of great significance, mainly during active decomposition phase. Indeed, after stabilization phase, total heavy metal concentrations is steady, indicating that leachability of heavy metal can be reduced; this demonstrates the interest of land application of mature compost. The variations in the heavy metals could be related to the properties of both metal and manure samples. Irshad et al. ${ }^{18}$ reported a decrease in the amount of water extractable heavy metals with the time of composting. Bolan et al. ${ }^{19}$ reported that the concentration of metals can vary considerably among animal manures. Additional variation is associated with the age of the animal, type of ration, housing type and waste management practices. Increase in metal concentration in animal feed have often resulted in higher concentration in the manure. The type of bedding material in animal wastes may influence the litter dry matter and other chemical properties ${ }^{20}$.

The largest proportion of heavy metal was associated with the residual fraction and fractions more resistant to extraction $\mathrm{X}-\mathrm{NaOH}, \mathrm{X}-\mathrm{EDTA}$ and $\mathrm{X}-\mathrm{HNO}_{3}$. This indicated that the metals were in more stable forms and can consequently be considered unavailable for plant uptake. Less percentage of heavy metals concentrations have been reported in bioavailable fractions $\left(\mathrm{KNO}_{3}+\right.$ $\left.\mathrm{H}_{2} \mathrm{O}\right)^{21}$. Eneji et al. ${ }^{13}$ found composted manure with higher $\mathrm{Fe}$ and lower $\mathrm{Cu}$ content. Huang et al. ${ }^{22}$ found a significant reduction in percentage of water soluble, extractable, carbonate and $\mathrm{Fe}-\mathrm{Mn}$ oxide fraction of $\mathrm{Cu}$ and $\mathrm{Zn}$, and an increase in organic and residual fraction of $\mathrm{Cu}$ and $\mathrm{Zn}$ in compost. Pare et al. ${ }^{23}$ reported decreases in the extractability of heavy metals during composting of biosolids and municipal solid wastes, indicating a 
reduced risk of their entering the food chain through crops and water.

Sequential extraction of metals indicated a decline in the soluble component and an increased in the residual, organically bound forms. The chemical forms or species, in which a metal is found in the manure may predict the insights on the bioavailability, mobility and fate of metals. Fractionation of metals in the soils affects their extractability as well as bioavailability. Therefore, metals in the extractable fractions would be readily bio-available to the environment, whereas the metals in the residual fraction are tightly bound and would not be expected to be released under natural conditions ${ }^{24}$.

Cationic trace elements normally react with certain organic molecules to form organometallic complexes called chelates. In general these complexes are not soluble, the metals are tightly held and bound. They are thus not available to plants. They could only be slowly released through decomposition process ${ }^{25}$. Ciavatta et al. ${ }^{\mathbf{1 6}}$ reported that $\mathrm{Cr}$ is the heavy metal that tended to be insolubilized during composting. Sequential extraction of metals indicated a decline in the soluble component and an increased in residual and organically bound forms ${ }^{23}$.

Heavy metals availability of soil depends on their distribution between solid and solution phase, which in turn is dependent on soil processes like cation exchange capacity, organic matter and $\mathrm{pH}$. The impact of organic matter amendments on heavy metal solubility depends greatly upon the degree of the humification of organic matter and their effect upon soil $\mathrm{pH}^{17}$. In general, the amount of an element in the soil solution is believed to depend on the equilibrium between the soil solution and solid phase, with $\mathrm{pH}$ playing the decisive role.

\section{CONCLUSIONS}

The study concludes that throughout the composting process, heavy metals reached relatively stable levels reflecting the stability and maturity of the final product. The total concentrations of heavy metals were relatively low rendering final compost acceptable for agricultural use. Fractionation of heavy metals showed that heavy metals concentrations in the manure were dependent on the days of composting. The largest proportion of metal was found in the residual fraction and fractions more resistant to the extraction indicating that the metals were in more stable forms and is consequently considered unavailable for plant uptake. Sequential analysis of heavy metals confirmed reduced extraction of these elements during the composting process. Higher concentrations of $\mathrm{Ca}, \mathrm{Mg}$ and $\mathrm{K}$ were observed manure samples during the later stages of composting.

\section{ACKNOWLEDGEMENT}

We highly appreciate the financial support made by the University of Haripur and the laboratory facility provided by the COMSATS Institute of Information Technology, Abbottabad for this study.

\section{LITERATURE CITED}

1. Asiriuwa, O.D., Ikhuoria, E.U., Omorogbe, S.O. \& Akpaja, E.O. (2013). Physico-chemical characteristics of poultry droppings and its effects on growth and yield of Sclerotia of Pleurotus tuberregium. Int. J. Environ. Sci. 2(4), 130-137.

2. Weber, J., Karczewska, A., Drozd, J., Licznar, M., Licznar, S., Jamroz, E. \& Kocowicz, A. (2007). Agricultural and ecological aspects of a sandy soil as affected by the application of municipal solid waste composts. Soil Biol. Biochem. 39, 294-1302. DOI:10.1016/j.soilbio.2006.12.005.

3. Singh, R.P. \& Agrawal, M. (2008). Potential benefits and risks of land application of sewage sludge. Waste Manage. 28, 347-358. DOI: 10.1016/j.wasman.2006.12.010.

4. Castaldi. P., Santona, L. \& Melis, P. (2006). Evolution of heavy metals mobility during municipal solid waste composting. Fresen. Environ. Bull. 15(9), 1133-1140.

5. Yobouet, Y.A., Adouby, K., Trokourey, A. \& Yao, B. (2010). Cadmium, copper, lead and zinc speciation in contaminated soils. Int. J. Eng. Sci. Tech. 2(5), 802-812. DOI: 10.1080/00103620009370502.

6. Singh. J. \& Kalamdhad, A.S. (2013). Chemical speciation of heavy metals in amended soil- A review. Int. J. Environ. Eng. Res. 2(2), 27-37.

7. Konradi, E.A., Frentiu, T., Ponta, M. \& Cordos, E. (2005). Use of sequential extraction to assess metal fractionation in soils from Bozanta Mare Romania. Acta Univ. Cabiniensis Ser. F. Chem. J. 8, 5-12.

8. Zufiaurre, R., Olivar, A., Chamorro, P., Nerin, C. \& Callizo, A. (1998). Speciation of metals in sewage sludge for agricultural uses. Analyst 123(2), 255-259. DOI: 10.1039/A705168I.

9. Tessier, A., Campbell, P.G.C. \& Bisson, M. (1979). Sequential extraction procedure for the speciation of particulate trace metals. Analyt. Chem. 51(7), 844-851. DOI: 10.1021/ ac50043a017.

10. Manios, T. \& Stentiford, E.I. (2006). Heavy metals fractionation during the thermophilic phase of sewage sludge composting in aerated static piles. J. Environ. Sci. Health Part A, 41, 1235-1244.

11. Stover, R.C., Sommers 1.E. \& Silviera, D.J. (1976). Evaluation of metals in wastewater sludge. J. Water Poll. Control Fed. 48, 2165.

12. SAS (1999). StatView Reference. $3^{\text {rd }}$ Ed. SAS Institute Inc., Cary, NY, USA.

13. Eneji A.E., Yamamoto, S., Honna, T. \& Ishiguro, A. (2001). Physicochemical changes in livestock feces during composting. Commun. Soil Sci. Plant Anal. 32(3-4), 477-489. DOI: 10.1081/ CSS-100103023.

14. Eneji, A.E., Honna, T., Yamamoto, S. \& Masuda, T. (2003). Influence of composting conditions on plant nutrient concentrations in manure compost. J. Plant Nutr. 26(8), 1595-1604. DOI: 10.1081/PLN-120022369.

15. Petruzzeli, G, Scymura, I., Lubrano, I. \& Pezzarossa, B. (1989). Chemical speciation of heavy metals in different size fraction of compost from solid urban waste. Environ. Technol. Letters 10, 51-526. DOI: 10.1080/09593338909384768.

16. Caviatti, C., Govi, M., Simoni, A. \& Sequi, P. (1993). Evaluation of heavy metal during stabilization of organic matter in compost produced with municipal solid wastes. Biores. Technol. 43, 147-153. DOI: 10.1016/0960-8524(93)90174-A.

17. Wong, J.W.C. \& Fang, M. (2000). Effect of lime addition on sewage sludge composting process. Water Res. 34(15), 3691-3698. DOI: 10.1016/S0043-1354(00)00116-0.

18. Irshad, M., Shazia, G., Eneji, A.E., Anwar, Z. \& Ashraf, M. (2014). Extraction of heavy metals from manure and their bioavailability to spinach (Spinacia oleracea L.) after composting. $J$. Plant Nutr. 37, 1661-1675. DOI: 10.1080/01904167.2014.888748. 19. Bolan, N.S., Adriano, D.C. \& Mahimairaj, A.S. (2004). Distribution and bioavailability of trace elements in livestock and poultry manure by-products. Crit. Rev. Environ. Sci. Technol. 34, 291-338. DOI: 10.1080/10643380490434128.

20. Nicholson, F.A., Chambers, B.J., Williams, J.R. \& Unwin, R.J. (1999). Heavy metal contents of livestock feeds and animal 
manures in England and Wales. Biores. Technol. 70, 23-31. DOI: 10.1016/S0960-8524(99)00017-6.

21. Ahmed, M., Idris, A.S. \& Omar, R.S. (2007). Physico-chemical characterization of compost of the industrial tannery sludge. J. Eng. Sci. Tech. 2, 81-94.

22. Huang, G.F., Wong, J.W.C., Nagar, B.B., Wu, Q.T. \& Li, F.B. (2005). Bioavailability of heavy metals during humification of organic matter in pig manure compost (http://www.eco-web. com/edi/index.htm).

23. Pare, T., Dinel, H. \& Schnitzer, M. (1999). Extractability of trace metals during co-composting of biosolids and municipal solid waste. Biol. Fert. Soils 29, 31-37. DOI: 10.1007/ s003740050521.

24. Uwumarongie-Ilori, E.G., Aisueni, N.O., Sulaiman-Ilobu, B.B., Ekhator, F., Eneje, R.C. \& Efetie-Osie, A. (2012). Immobilization effect of cow dung on lead and chromium in soil cultivated with oil palm. Bull. Environ. Pharmacol. Life Sci. 1(9), 74-80.

25. Urunmatsoma, S.O.P., Ikhuoria, E.U. \& Okieimen, F.E. (2010). Chemical fractionation and heavy metal accumulation in maize (Zea mays L.) grown on chromated copper arsenate (CCA) contaminated soil amended with cow dung manure. Inter. J. Biotechnol. Mol. Biol. Res. 1(6), 65-73. 